\title{
Problems of the Program for Teaching Female Deaf Students at the College of Education for Home Economy and Technical Education at the University of Princess Noura Bint Abdulrahman in Riyadh
}

\author{
Ohoud Alshamsan \\ Social and Psychological Sciences, Riyadh, Saudi Arabia \\ Email: audi_m_s@hotmail.com
}

How to cite this paper: Alshamsan, O. (2017) Problems of the Program for Teaching Female Deaf Students at the College of Education for Home Economy and Technical Education at the University of Princess Noura Bint Abdulrahman in Riyadh. Open Journal of Social Sciences, 5, 92-105. https://doi.org/10.4236/jss.2017.59007

Received: August 15, 2017

Accepted: September 10, 2017

Published: September 13, 2017

Copyright $\odot 2017$ by author and Scientific Research Publishing Inc. This work is licensed under the Creative Commons Attribution International License (CC BY 4.0).

http://creativecommons.org/licenses/by/4.0/

\begin{abstract}
The researcher tried to discuss the problems related to female deaf students. The title of the study is "Problems of the Program for Teaching Female Deaf Students at the College of Education for Home Economy and Technical Education at the University of Princess Noura Bint Abdulrahman in Riyadh". In order to identify the program problems, the researcher, Ohoud Alshamsan, tried to answer the following research question: what are the problems of programs for teaching female deaf students (FDS) at the college of education for home economy and technical education (CEHETE) at the University of Princess Noura Bint Abdulrahman in Riyadh? Research Population: The population of the study consisted of the teaching staff and FDS at the CEHETE in the University of Princess Noura Bint Abdulrahman in Riyadh. The population of the study consisted of 38 members of the teaching staff and 25 participants of the FDS. The study sampling included the afore-mentioned population, which comprises of 33 teaching staff and 20 FDS. Methodology: The researcher used the descriptive analytical approach and a questionnaire for data collection in answering the main question of the study. The data were analyzed and categorized using the SPSS program which yielded to the following results: Results of the Study: 1) There are no statistically differences at level 0.05 in the attitudes of the interviewees towards the FDS problems. 2) There are no statistically differences at level 0.05 in the attitudes of the interviewees with respect to the FDS academic problems. 3) There are no statistically differences at level 0.05 in the attitudes of the interviewees towards the
\end{abstract}


FDS administrative problems. Main Recommendations: Based on the results of the study, the following recommendations emerged: 1) Recruiting more special education female teachers with specialization in "deaf handicapped education". 2) Recruiting more special education female teachers with specialization in "sign language". 3) Cooperating with societies concerned with these programs should be resorted to compensate for lack of specialist in this vital area. This kind of cooperation is likely to strengthen higher education programs for teaching deaf and weak hiring female students. 4) Signing contracts with female teacher specializing in deaf education or with female interpreters specializing in sign language.

\section{Keywords}

Problems, Program, Education, Deaf Students, University of Princess Noura Bint Abdulrahman

\section{Introduction}

Providing literacy for all members of society is the main goal of any state. In this respect, the kingdom of Saudi Arabia listed education at the top of its priorities. Many educational institutions were open since the establishment of the Kingdom. Nowadays, both males and females have the same opportunity to pursue higher education. Students with special needs in Saudi Arabia do find places for them in the widespread institutions in the Kingdom. The right for education is not only guaranteed for general students. Students with different levels of disability now find open opportunities in the Saudi educational institutions as well. The philosophy of education in the kingdom is derived from the teachings of Islam.

Pursuing higher education for both genders is the dream of any student. However, there are some problems and challenges that encounter the higher teaching programs for the deaf and the hard hearing students for both genders. The Ministry of Education in Saudi Arabia paid tremendous efforts in designing and opening new programs for the deaf and hard hearing students especially for the females. Such problems represent a real challenge for the deaf and hard hearing students who finished the secondary education and who try to continue their higher education.

The literature in this study indicated that many of the hard hearing and deaf students find it difficult to pursue their higher education in many institutions in different Arab countries. The reasons associated with the difficulties to continue the higher education for the deaf and the hard hearing students are due to laws and regulations constraints which pose difficulties in front of this category of people to continue their higher education.

The researcher tried to shed the light on the challenges and identify the problems of the programs for teaching the FDS at the CEHETE in the University of 
Princess Noura Bint Abdulrahman in Riyadh district. It is worth mentioning that there are no precise statistics for those who are deaf or hard hearing students who try to pursue their higher education. The researcher attributed the lack of such statistics to some cultural and social constraints in the Arab communities.

\section{Research Problem}

In Saudi Arabia, the female deaf students were given the opportunity to continue their higher education at one of the universities. To achieve this purpose, the University of Princess Noura Bint Abdulrahman in Riyadh opened the admission for the female deaf students in CEHETE during 1425 Hijri. Although the experiment was successful in the opinions of many, the program in the faculty was suspended for different reasons.

The research problem is that programs for teaching the FDS at the CEHETE at the University of Princess Noura Bint Abdulrahman in Riyadh face many problems. Therefore, the researcher tried to identify such problems aiming at reaching reasonable solutions and recommendations.

To be more specific, the researcher narrowed down the research problem in the following question: what are the problems of the programs for teaching the FDS at the CEHETE in the University of Princess Noura Bint Abdulrahman. The following three sub-questions emerged from the main question of the research:

1) What are the problems that prevented the continuation of the programs for teaching FDS at the CEHETE in the University Princess Noura Bint Abdulrahman as seen by the female teaching staff?

2) What are the problems that prevented the continuation of the programs for teaching FDS at the CEHETE in the University of Princess Noura Bint Abdulrahman as seen by female deaf students?

3) Are there significant differences at level 0.05 in the problems that prevent the continuation of the programs for teaching FDS at the CEHETE between the female deaf students and the female teaching staff?

\subsection{Research Aims}

The study tried to achieve the following aims:

1) To identify the problems that prevented the continuation of the programs for teaching the FDS at the CEHETE in the University of Princess Noura Bint Abdulrahman from the perspectives of faculty members.

2) To detect and identify of problems that prevented the continuation of the programs for teaching the FDS at the CEHETE in the University of PrincessNoura Bint Abdulrahman from the point of view of deaf students.

3) To identify the differences of the statistical significance at level 0.05 in the attitudes of the problems that prevented the continuation of the program between the female teaching staff and deaf students at the CEHETE in the University of Princess Noura Bint Abdulrahman. 


\subsection{Significance of the Study}

The significance of the study stems from its importance in the Saudi community as being one of the few studies that tackled the issue of the deaf students on the university level. The importance of this study also comes from its methodology, which tries to prove the efficiency of the teaching programs for female deaf students in Saudi Arabian universities. In addition, the study is important as it identified the real problems that form a challenge in the continuation of the programs for teaching the FDS at the CEHETE in the University of Princess Noura Bint Abdulrahman in Riyadh district. Moreover, there are few studies in Saudi Arabia that discussed such issues, so the importance of this study lies in its findings, which may form the basis for future similar studies. The study will also increase the awareness of the concerned parties about the importance of the higher education for female deaf students in light of their rights and the development of services provided to them in the Kingdom of Saudi Arabia in accordance with international laws. Most importantly, the study results will help the decision makers in the Ministry of Education to take the necessary procedures and regulations for the favor of the success of the education programs for the deaf students in the kingdom.

\subsection{Research Limitations}

The study will be conducted within the following limitations:

1) Objective limitations: The study tackled the problems of programs for the FDS at the CEHETE in the University of Princess Noura Bint Abdulrahman in Riyadh.

2) Population limitations: The population of the study was the female deaf students and the female teaching staff at the CEHETE in the University of Princess Noura Bint Abdulrahman in Riyadh.

3) Place limitations: The study was conducted at the CEHETE in the University of Princess Noura Bint Abdulrahman in Riyadh.

4) Time limitations: The study was conducted during the second semester in the school year 2013.

\subsection{Operational Definitions}

For the purposes of this study, the researcher defined the following idioms and concepts operationally:

1) Problems: All the factors, circumstances and difficulties that prevent deaf students from pursuing their university education and reaching the required level and obtaining a university degree.

2) Education: A type of formal education that follows the secondary stage for a period of, at least, two academic years which is submitted by the specialized institutions that grant a verified certificate.

3) Deaf students: They are the female students who have hearing impairment wholly or partially and who struggle at the university due to their deafness disability. 
4) Deaf Education Program at the College of Education for Home Economics and Art Education at the University of Princess Noura Bint Abdulrahman University in Riyadh: Is a designed program for enrolling female deaf students for the higher education studies at the CEHETE in the University of Princess Noura Bint Abdulrahman in Riyadh.

\section{Literature Review}

The researcher reviewed many articles and studies before commencing on this study. The aim was to get the necessary information related to this study. Some studies approached the topic in different way. It is worth stating that there are few studies that tackled the issue of the difficulties that face the female deaf students in the Saudi Universities. However, the study by Masoud (1999) [1] indicated that the integration of deaf students was difficult at the beginning of the study but changed for the better in the second year. This was based on several factors, the most important of which is the high motivation for the deaf students towards pursuing higher learning. Another study by Liversidge (2003) [2] revealed that when deaf and hearing-impaired students are positively integrated into university life, they are likely to achieve a high level of commitment to be successful. In this domain, the study by Almuheiri (2007) [3] revealed that the attitudes of ordinary teachers, whether in the group that participated in the integration process or the group that did not participate in the integration process were negative, although the group that participated in the integration of the deaf was dealing with students with hearing impairment directly, but did not change their direction. However, the study by Omar (2008) [4] pointed out that the areas of problems of higher education are varied. According to the sample of the study, the areas related to the negative attitudes of the university society and the low expectations of the teachers from the deaf students are the most severe problems. Other studies, such as the study by Alkharji (2010) [5] indicated that the faculty members agreed on the existence of some obstacles such as: failure to equip classrooms with warning light signals, and the lack of training programs that raise the level of faculty members in the field of teaching the deaf and hearing impaired, and lack of knowledge about research and educational publications related to the deaf and hearing impaired.

The researcher believed that these studies are relevant to the topic especially as they discuss some problems related to the implementation of educational programs for the deaf. The researcher will use these studies to support in the process of conducting this study.

\section{Methodology}

The study used the descriptive analytical approach and the questionnaire methodology for data collection in answering the main question of the study since it best suits the study objectives. The descriptive method enabled the researcher to study the problem in depth and identify the relations between the study 
variables. In addition, the descriptive approach helped the researcher identify the reality of the research problem by providing a precise description about it and collecting important information as well as identifying the views of the study population.

To implement this methodology, the researcher defined the study population, which consisted of all the teaching staff and the FDS at the CEHETE in the University of Princess Noura Bint Abdulrahman. Therefore, the population of the study consisted of 38 members of the teaching staff numbered and 25 participants of the FDS. The study sampling included the afore-mentioned population, which comprises of 33 teaching staff and 20 FDS. The researcher displayed the data, which are related to the demographic variables of the sample in tables.

The researcher distributed surveys among the sample of the study. A total of 53 surveys were completed by the female faculty members and the female deaf students in the University of Princess Noura Bint Abdulrahman. The researcher collected the surveys and the data were processed by using the scientific packages for social sciences (SPSS) program.

\section{Research Tool}

The researcher used the survey as the main tool for collecting the data from the population of the study since it is the best way of getting and collecting the necessary data. The researcher believed that the best way to communicate ideas with the deaf female students is only possible through the survey method where the deaf female students expressed their ideas freely.

The researcher designed a survey that assesses and identifies important challenges in the program for educating the deaf female students at the University of Princess Noura Bint Abdulrahman. The design of the survey was based on the researchers headings of different theses and dissertation about the topic. The items of the survey were designed so as they provide an easy way to respond to them and they were connected with the research questions and objectives.

The survey consisted of all the necessary instructions that provide an easy way for the participants to respond to its items. The researcher related all the study questions and objectives in designing the items of the survey. Moreover, the researcher used the Likert Scale ranging from 1 - 5 in assessing and identifying the problems of the program for teaching FDS at the CEHETE in the University of Princess Noura Bint Abdulrahman.

\section{Research Tool Design}

The researcher referred to a number of relevant literatures about the topic in formulating the research question and the research objectives. The research methodology was defined after the researcher had identified the main question and objectives of the study.

The researcher relied on its own personal experience in the topic as well as on different readings from dissertations and thesis about the topic while designing 
the items of the survey. The researcher conducted some unofficial telephone talks and interviews with a number of female faculty members and deaf students so as to collect some important details about the topic.

The survey was approved by faculty members at the university after the researcher had modified some items according to the faculty members' remarks. The survey comprised of two parts each of which addressed both the female teaching staff and the deaf students at the University of Princess Noura Bint Abdulrahman.

The first part of the survey was devoted for the demographic variables related to the female teaching staff. The variables included, the age, the best way to deal and communicate with the deaf students, agreement or disagreement of teaching the deaf students and agreement or disagreement of enrolling in special workshops abut coping with deaf students. The variables related to the female deaf students were the age, the level of deafness, presence of other disabilities, having hearing aids or not, type of education before the high stage of education, specialization, the department and the year of graduation from the university.

The second part of the survey consisted of 70 items distributed on 5 domains for both the female teaching staff and the female deaf students. The domains included the following:

1) Academic problems domain which included 27 items of the survey.

2) Administrative problems domain which included 7 items of the survey.

3) Social problems domain which included 10 items of the survey.

4) Psychological problems domain which included 19 items of the survey.

5) Economical problems domain which included 9 items $f$ the survey.

The researcher used the Likert Scale in identifying the items of each domain of the survey.

\section{Data Collection and Analysis}

The researcher used the survey method to collect the data from the sample of the study. The researcher distributed the surveys among the sample of the study. In addition, the researcher conducted a number of unofficial interviews with both the female deaf students and the female teaching staff at the University of Princess Noura Bint Abdulrahman. The researcher used the SPSS in processing the data. Means, standard deviations and Alpha Cronbach and T-Tests were used to assess and calculate the responses and the attitudes of the sample of the study to the items of the survey. The researcher used the Likert Scale in the survey to assess the attitudes of the participants on the items of the survey. In presenting the data, the researcher categorized them into tables so as to enable easy access and comparison in assessing the sample attitudes. The results were displayed according to the five domains of the study. The researcher discussed and commented on the results with reference to each domain of the study.

\section{Results}

The study aimed at identifying the components of the programs for teaching the 
FDS at the CEHETE in the University of Princess Noura Bint Abdulrahman in Riyadh district. The study also tried to identify the problems in implementing such programs for teaching the deaf students from the female teaching staff perspectives and from the female deaf students' perspectives in the University of Princess Noura Bint Abdulrahman. The researcher collected and analyzed the necessary data for the study, which were related to the study questions and aims. The study revealed the following results.

The general results of the study were related to the study questions and aims. The following are the main results that emerged from the study:

1) There are no statistically differences at level 0.05 in the attitudes of the interviews towards the FDS problems.

2) There are no statistically differences at level 0.05 in the attitudes of the interviewees with respect to the FDS academic problems.

3) There are no statistically differences at level 0.05 in the attitudes of the interviewees towards the FDS administrative problems.

\section{Discussion of Results}

The researcher used tables in order to find the relationship between the study variables. The tables enabled he researcher to cake some comparison between the results with reference to the five domains of the study. Anyhow, the researcher presented the results of the study in two sections-the first section was devoted for presenting the results related to the sample of the study, the other section was merely devoted to present the findings of the study according to the three research questions.

The following are the discussion of the results related o the sample of the study:

\subsection{Discussion and Description of the Study Population}

1) The results revealed that 17 of the female teaching staff preferred resort to a translator while communicating with the female deaf students. The teaching staff represents $51.5 \%$ of the total teaching staff.

2) About $93.9 \%$ of the female teaching staff agree that female deaf students should continue their higher education.

3) The data indicated that 30 female teachers, who comprise $90.9 \%$ of the teaching staff sample, did not receive any training in dealing and coping with the deaf students.

4) The female deaf students whose ages range from 26 - 30 have hearing impairments and they represent $55.3 \%$ of the total student population the CEHETE in the University of Princess Noura Bint Abdulrahman.

5) A number of the deaf students who do not have other disabilities except for the deafness represent $75.0 \%$ and whose favorite means of communication is the total communication based on different social settings.

6) The results revealed that $80.0 \%$ if the total deaf students population wear 
hearing devices and $100 \%$ of them did have pre-education at one of the institutes for the deaf in Saudi Arabia.

7) The data indicated that $10 \%$ of the female deaf students population are specialized in arts and another $10 \%$ of the deaf students have specialization in house administration.

\subsection{Discussion of the Results According to the Research Questions}

(A) The results related to the first question of the study, which states, "what are the problems that prevented the continuation of the programs for teaching FDS at the CEHETE in the University of Princess Noura Bint Abdulrahman as seen by the female teaching staff?" Indicated the following findings with reference to the academic problems domain.

1) The study sample, the female teaching staff, were neutral in their responses to the items of the survey in the academic problems domain. The average of the responses was 3.24 in the Likertscale, which indicates to the choice "I don't know" of the survey scale.

2) There were significant differences in the responses of the female teaching staff to the items of the survey in the academic problems domain. The average responses ranged between $2.03-4.09$ of the survey scale, which indicate that "there are problems" related to the academic domain in preventing of the continuation of the program for teaching the FDS to "no problems".

The previous result indicted that the female teaching staff hold different perspectives on 10 items of the survey related to the academic problems domain. The differences between the female teaching staff responses were on the following items of the survey: $(19,21,27,23,12,17,25,16,22,26)$. The items were sorted according in the descending order according to the level of the problem.

Item (19) occupied the first rank in the academic problems domain as seen by the female teaching staff. It is related to the lack and shortage of the devices and materials that the female deaf student needs. The sample average responses were 4.09 on the survey scale. The researcher explained that this result indicates the importance of providing the female deaf students with the necessary services and tools so as to make the process of communicating and teaching this category of students easy and effective.

The other items were related to variety of issues, such as the lack of training for both the students and the staff, the unavailability of the modern equipment and services that might help the deaf, the lack of the necessary skills for the teaching staff in coping with the deaf students, the absence of the academic devising for the deaf students and the topics of the curricula do not satisfy the needs of the deaf students.

3) The female teaching staff had no idea about the level of problems in 15 issues that the FDS at the CEHETE face. Such issues are related to the female deaf students' academic needs, such as the need to understand the lectures, difficulty in taking notes during lectures, weakness in writing and reading skills, exams are 
difficult for the deaf students and the need to understand the sign language in a proper way.

4) The female teaching staff holds similar perspectives on two issues related to the academic domain. They agree that many of the teaching staff do not understand popery the sign language which they may use to communicate with the deaf girls. In addition, the teaching staff agrees that the textbooks they use to teach the deaf students do not suit the students' abilities.

The results related to the second domain, administrative problems, of the study indicated that the female teaching staff has the same agreement on the presence of problems related to administrative procedures. The administrative problems included issues, such as the unavailability of the places for the deaf students where they can do extracurricular activities, the lack o regulations and laws that cares for the deaf students' affairs, the lack of time for the deaf students to go to the library and the absence of a specialized committee in the university who should follow up the deaf students' affairs.

The results related to the third domain, the social problems, of the study indicated that the female teaching staff shares the same ideas about the presence of social problems that affect the teaching of the female deaf students. However, the teaching staff hold different perspectives on the level of problems in issues related to the social constrains, such as the availability of clubs in the university for the deaf students, the university admission policy in accepting the female deaf students in the colleges of the university which is mostly based on the average of the students' scores rather than the students' real needs and the lack of communication in the university between the deaf students and their general peers.

The results of the study in the social domain are supported by the results of the studies by Almuheiri (2007) [3], Hanafi (2008) [6] and Leversedge (2003) [2] which all claimed that the social problems affect the implementation of any program for teaching the deaf.

The results related to the fourth domain, psychological problems revealed that the teaching staff at the university shares the same opinions on the availability of psychological problems that affect the teaching of the female deaf students negatively. However, the teaching staff had no idea about the level of the problems in 14 issues related to the psychological aspect of the deaf students. The psychological problems were related to the anxiety of the students during examinations, the feeling of being not accepted by the general peers, the lack of concentration in lectures, the feeling of isolation most of the time and the feeling of being monitored by their general peers. The results of the study in the psychological domain are consistent with the results of the studies by Massoud (1999) [1], Almuheiri (2007) [3] and Omar (2007) which all agree that the psychological problems hinder the continuation of teaching program for the female deaf students.

The results related to the fifth domain, economic problems, of the study indicated that all the teaching staff agrees that the economic problems affect negatively 
the implementation of the program for teaching the FDS at the CEHETE. The economic problems were related to different issues, such as the cost of transportation for the deaf student to and from e university, unavailability of employment for the deaf student in the same university after graduation and the high cost of the services needed for teaching he deaf students compared with the cost of teaching their general peers.

(B) The results related to the second question of the study which states "what are the problems that prevented the continuation of the programs for teaching FDS at the CEHETE in the University of Princess Noura Bint Abdulrahman as seen by the female deaf students?" revealed the following findings with respects to the five domain of the study.

1) The results of academic domain indicated that all the female students share the same worries bout he presence of the academic domains which form a real challenge for them to continue their education. The academic issues included the inability o follow up teachers during the lectures, difficulties in taking notes, curricula do not satisfy all the deaf needs, the traditional teaching methods that do not pay much attention to the deaf needs, lack of academic advising in the department and difficulties in reading and writing skills for a group of the deaf students. He results of the study in this domain are consistent with those in the studies by Massoud (1999) [1] and Almuheiri (2007) [3].

2) The results that emerged from the administrative domain indicated that all the deaf students share the same attitudes towards a number of administrative problems that constitute a real challenge for them in continuing their higher education. However there were some differences in the opinions of the sample with respect to the level of the administrative problems such as, the lack of meetings between the administration in the university and the deaf students, the lack of recreation and counseling services and the absence of the extracurricular activities for the deaf students.

3) The results related to the social domain revealed that there were differences in the responses of the deaf students on specific items in the social domain. The items are related to social issues, such as the participation in the activities, being ignored, unavailability of special needs for the deaf students and the unavailability of a social and cultural clubs in the university that may help the deaf to be socially successful.

4) The results from the psychological domain revealed that all the deaf students agree on the presence of the psychological problems that prevent them from continuing their higher education. However, the results revealed that there are some differences in the responses of the sample on specific items in the psychological domain. These items are related to the anxiety and tension during the exams period and the fear from failure in the college.

5) The results that emerged from the economic domain indicated that the female deaf students share the same concerns about the items in the economic domain. However, there were some differences in the responses of the sample on 
some items related to the possibility of finding a job in the market after graduation. The sample claimed that the university did not pay much effort in providing the deaf students with a transition program that might qualify them for future jobs.

(C) The results related to the third question of the study, which states, "are there significant differences at level 0.05 in the problems that prevent the continuation of the programs for teaching FDS at the CEHETE between the female deaf students and the female teaching staff?" indicated the following;

1) There are no statistically differences at level 0.05 in the attitudes of both the female teaching staff and the female deaf students on the academic, administrative and economic domains.

2) There are differences at the level 0.05 in the attitudes of both the female teaching staff and the female deaf students on the social domain for the favor of the deaf students.

3) There are differences at the level 0.05 in the attitudes of both the female teaching staff and the female deaf students on the psychological domain for the favor of the teaching staff.

\section{Recommendations}

Based on the results of the study, the following recommendations emerged:

1) Adopting a flexible admission policy in the universities for accepting deaf students in an inviting way.

2) Recruiting more special education female teachers with specialization in "deaf handicapped education".

3) Recruiting more special education female teachers with specialization in "sign language".

4) Cooperating with societies concerned with these programs should be resorted to compensate for lack of specialist in this vital area. This kind of cooperation is likely to strengthen higher education programs for teaching deaf and weak hiring female students.

5) Signing contracts with female teacher specializing in deaf education or with female interpreters specializing in sign language.

6) Offering the female deaf students with the necessary information about the available specializations in the university.

7) Recruiting more specialized teaching staff and raining them in how to communicate and deal with the female deaf students.

8) Recruiting female translators in the sign language as this helps a lot the female deaf students especially in everyday communication with the other general students and with the teaching staff.

9) Equipping especial resource rooms for the deaf students so as they can use the necessary equipment and services related to their specialization.

10) Training the female teaching staff on the new teaching methodologies suitable for teaching the deaf students. 


\section{Conclusion}

The researcher concluded that the programs for teaching the FDS at the CEHETE in the University of Princess Noura Bint Abdulrahman in Riyadh face many problems. The problems were attributed to many issues related to the female deaf students and the female teaching staff at the CEHETE in the University of Princess Noura Bint Abdulrahman. The researcher collected the data by using the survey method, which was distributed among the sample of the study. The researcher processed the data using the SPSS program and the results revealed many problems that prevented the continuation of the programs for teaching the FDS at the CEHETE in the University of Princess Noura Bint Abdulrahman. The problems were categorized into five domains-academic, social, economic, psychological and administrative domains. The results revealed that there were differences in the responses of the sample on the items of the survey in the five domains of the study. The results also indicated that the problems that prevent the continuation of the program for teaching the FDS at the CEHETE in the University of Princess Noura Bint Abdulrahman do exist and that there are some female teaching staff that are not aware of them. The study concludes by recommending some suggestions for the benefit of continuing such programs for the female deaf students.

\section{Acknowledgements}

The researcher would like to thank those who helped her in conducting this study. Special thanks are to the female deaf students and the female teaching staff at the University of Princess Noura Bint Abdulrahman for their cooperation in conducting this study especially when they welcome the researcher to conduct a number of unofficial interviews. In addition, the researcher is grateful for those who helped her in distributing ad responding to the surveys. Most importantly, the researcher would like to extend her gratitude for her supervisors who helped and guided her throughout the process of conducting this study.

\section{References}

[1] Masoud, M. (1999) Experience of Deaf Education at the Intermediate University of Princess Rahma College of Social Service, Balqa Applied University. Al Riyadh. Published Research, 25-27. [Translated]

[2] Liversidge, A. (2003) Academic and Social Integration of Deaf and Hard Hearing Students in Academic Research. IUniversity proquest Dissertations and Theses.

[3] Almuheiri, A. (2007) Attitudes of Teachers towards the Integration of the Hearing Impaired in Regular Schools. Published Research. The United Arab Emirates. Journal of Faculty of Education. United Arab Emirates University. Twenty-Third Year. Issue 25. [Translated]

[4] Omar, A. (2008) Difficulties of Higher Education among People with Hearing Loss and the Requirements to Cope with Them. Research presented to the Eighth Scientific Symposium of the Arab Federation of Dealing Organizations Entitled "Development of Education and Rehabilitation of Deaf and Hearing Impaired Persons" in 
the period 22-24 April 1429, Hijri. [Translated]

[5] Alkharji, M. (2010) Reality and Constraints of Higher Education Programs for Deaf and Hard of Hearing Students in Riyadh City. Master Thesis, King Saud University. [Translated]

[6] Hanafi, A. (2008) The Requirements of Integrating Deaf Students in the Ordinary School from the Point of View of Workers in the Field of Educating the Deaf. The 8th Scientific Symposium of the Arab Federation of Deaf Organizations (Development of Education and Rehabilitation of Deaf and Hearing Impaired Persons). Riyadh. King Fahad, Cultural Center. During the period from 28 to 30 April. [Translated]

Submit or recommend next manuscript to SCIRP and we will provide best service for you:

Accepting pre-submission inquiries through Email, Facebook, LinkedIn, Twitter, etc. A wide selection of journals (inclusive of 9 subjects, more than 200 journals)

Providing 24-hour high-quality service

User-friendly online submission system

Fair and swift peer-review system

Efficient typesetting and proofreading procedure

Display of the result of downloads and visits, as well as the number of cited articles Maximum dissemination of your research work

Submit your manuscript at: http://papersubmission.scirp.org/

Or contact jss@scirp.org 